\title{
A 20-year experience of 1712 patients with the Biocor porcine bioprosthesis
}

\author{
Pia S. U. Mykén, MD, PhD, ${ }^{\text {a }}$ and Odd Bech-Hansen, MD, $\mathrm{PhD}^{\mathrm{b}}$
}

Objective: The 20-year data from the ongoing long-term study of the St Jude Medical Biocor (St Jude Medical, St Paul, Minn) porcine bioprosthesis are reported. Earlier follow-ups have shown that the valve has excellent durability. After 20 years, will this continue to be true?

\begin{abstract}
Methods: Data were obtained for 1712 patients who underwent valve replacement (1518 aortic valve replacements; 194 mitral valve replacements) with glutaraldehyde-preserved Biocor bioprostheses at Sahlgrenska University Hospital (Sweden) between 1983 and 2003. Follow-up after surgery was evaluated on alternate years using hospital records, interviews, and questionnaires.

Results: At 20 years, the cumulative follow-up was 8843 and 1195 patient-years for aortic valve replacement and mitral valve replacement, respectively. Survival after aortic valve replacement was $17.7 \% \pm 3.3 \%$, and survival after mitral valve replacement was $16.4 \% \pm 4.7 \%$. Actuarial freedom from reoperation because of structural valve deterioration was $61.1 \% \pm 8.5 \%$ and $79.3 \% \pm 6.0 \%$ after aortic valve replacement and mitral valve replacement, respectively. (The equivalent actual/cumulative values were $85.6 \% \pm 2.2 \%$ and $91.2 \% \pm 2.6 \%$, respectively.) In aortic valve recipients aged 65 years or less and more than 65 years, actuarial freedom from reoperation because of structural valve deterioration was $44.5 \% \pm 9.2 \%$ and $92.1 \% \pm 3.9 \%$, respectively. The equivalent values in mitral valve recipients were $75.2 \% \pm 7.6 \%$ and $88.0 \% \pm 8.1 \%$, respectively.
\end{abstract}

Conclusion: The 20-year data confirm the excellent valve durability reported at the 17 -year follow-up after both aortic valve replacement and mitral valve replacement using the Biocor porcine bioprosthesis.

Close to 40 years after the introduction of bioprosthetic cardiac valves, prosthesis selection remains complex and must take into account each patient's individual needs. The first choice facing a cardiac surgeon is whether to use a mechanical valve-requiring the patient to undergo lifelong anticoagulant therapy with a subsequent risk of bleeding complications - or a bioprosthetic valve, with its potential risk of reoperation within 10 to 15 years because of tissue failure. ${ }^{1}$ Patients aged more than 65 years have a relatively low risk of calcification and valve failure, which minimizes the risk of reoperation during their lifetime, and so are increasingly receiving bioprosthetic valves. ${ }^{1}$ Mechanical valves are widely used for patients aged less than 65 years, although long-term anticoagulant use remains a concern. ${ }^{1}$ This has become enough of an issue in recent years that it is now more common to use bioprostheses in younger patients. It is impossible to predict whether this development will improve patient outcomes.

From the Departments of Thoracic and Cardiovascular Surgery ${ }^{\mathrm{a}}$ and Clinical Physiology, ${ }^{\mathrm{b}}$ Sahlgrenska University Hospital, Gothenburg, Sweden.

This study was supported by the Swedish Heart and Lung Foundation and St Jude Medical.

Received for publication Oct 29, 2007; revisions received April 23, 2008; accepted for publication May 28, 2008.

Address for reprints: Pia S. U. Mykén, MD, PhD, Department of Thoracic and Cardiovascular Surgery, Sahlgrenska University Hospital, SE-413 45 Gothenburg, Sweden (E-mail: pia.myken@swipnet.se).

J Thorac Cardiovasc Surg 2009;137:76-81

$0022-5223 / \$ 36.00$

Copyright (c) 2009 by The American Association for Thoracic Surgery

doi:10.1016/j.jtcvs.2008.05.068
The choice of prosthesis is both supported, and further complicated, by emerging data from long-term studies of both porcine and pericardial valves. ${ }^{2-4}$ These studies are yielding much-needed information on valve durability, which should be the primary consideration for most patients. ${ }^{2-4}$

Previous publications on the Biocor porcine prosthesis $(\mathrm{St}$ Jude Medical, St Paul, Minn) have demonstrated that it performs well and has good durability for up to 17 years after implantation. ${ }^{5-10}$ This article reports outcomes at the 20-year follow-up from an ongoing long-term prospective study. ${ }^{5-8}$

\section{MATERIALS AND METHODS}

The design and methods of this study have been outlined in previous publications. $^{5-8}$

\section{Patients}

This report includes data on consecutive patients who underwent either aortic valve replacement (AVR) $(\mathrm{n}=1518)$ or mitral valve replacement (MVR) $(n=194)$ at Sahlgrenska University Hospital, Gothenburg, Sweden, between January of 1983 and January of 2003. Informed consent was obtained from each study participant. All patients in this study received a Biocor bioprosthesis preserved in glutaraldehyde at low pressure, none of which had been "No-React" treated. The Biocor valve was the only bioprosthesis used at the Sahlgrenska University Hospital during this period of time. Approximately $30 \%$ of our patients undergoing cardiac valve replacement received a bioprosthesis and $70 \%$ received mechanical valves during the study period. Baseline patient characteristics are shown in Table 1.

\section{Surgical Procedures}

Operative procedures, prophylactic antibiotic therapy, and anticoagulation were standardized as described previously. ${ }^{5-8}$ Patients received anticoagulation with warfarin for 3 months from the second day after surgery with 


\section{Abbreviations and Acronyms}

$\mathrm{AVR}=$ aortic valve replacement

$\mathrm{CABG}=$ coronary artery bypass grafting

MVR $=$ mitral valve replacement

SVD = structural valve deterioration

the goal of maintaining the international normalized ratio value between 2.0 and 3.0.

\section{Follow-up}

Patients received follow-up questionnaires, and additional phone calls if needed, on alternate years from the time of their operation. Data were collected from medical charts (including all data for any suspected complication), autopsy reports (obtained for $\sim 50 \%$ of all deaths), or death certificates.

\section{Data Analysis}

Patient data were assessed and valve-related complications were defined according to The Society of Thoracic Surgeons and American Association for Thoracic Surgery Guidelines (1996 revision). ${ }^{11}$ Only actuarial data have been used to plot figures, in line with published guidance. ${ }^{12}$ At 20 -year follow-up, we also used linearized event rates to represent the number of complications per 100 patient-years.

\section{RESULTS}

The follow-up was $99.9 \%$ complete, and the cumulative follow-up times were 8843 and 1195 patient-years for AVR and MVR, respectively. The mean follow-up times were $6.0 \pm 4.5$ years for AVR and $6.2 \pm 5.6$ years for MVR.

\section{Patient Survival}

Early mortality. Seventy-seven patients undergoing AVR and 25 patients undergoing MVR died while in hospital postoperatively or within 30 days if the patient was discharged from hospital. None of these early deaths can be regarded as valve-related.

Late mortality. There were 541 deaths in the AVR group and 93 deaths in the MVR group. Causes of late death are shown in Table 2.

The overall survival was $17.7 \% \pm 3.3 \%$ after AVR and $16.4 \% \pm 4.7 \%$ after MVR. Additional coronary artery bypass grafting (CABG) was linked to impaired survival compared with isolated valve replacement: Survival was $4.6 \% \pm$ $3.8 \%$ after AVR plus CABG versus $22.3 \% \pm 4.1 \%$ after isolated AVR, whereas survival was $15.5 \% \pm 7.1 \%$ after MVR plus CABG compared with $21.6 \% \pm 5.3 \%$ after isolated MVR.

There were 58 valve-related deaths (46 AVR recipients, 12 MVR recipients), as seen in Table 2. This corresponded to an incidence of $0.5 \%$ /patient-years and $1.0 \%$ /patientyears for patients undergoing AVR and MVR, respectively.

The rates of actuarial freedom from valve-related death were $84.3 \% \pm 6.9 \%$ and $88.0 \% \pm 4.0 \%$ for AVR and
TABLE 1. Patient demographics at baselines

\begin{tabular}{lcc}
\hline & AVR & MVR \\
\hline $\mathrm{N}$ & 1518 & 194 \\
Male/female & $964 / 554$ & $95 / 99$ \\
Age (y) & & \\
$\quad$ Mean & $70.8 \pm 10.9$ & $64.9 \pm 12.3$ \\
$\quad$ Median & 74 & 68 \\
$\quad$ Range & $16-88$ & $22-83$ \\
Concomitant CABG & $632(42 \%)$ & $65(34 \%)$ \\
Previous cardiac operations & $54(4 \%)$ & $32(16 \%)$ \\
Active infective endocarditis & $41(3 \%)$ & $13(7 \%)$ \\
Diagnosis & & \\
$\quad$ Aortic insufficiency & 188 & \\
Aortic stenosis & 1116 & \\
Mixed & 214 & 133 \\
Mitral insufficiency & & 32 \\
Mitral stenosis & & 29 \\
$\quad$ Mixed & & \\
NYHA classification & & 20 \\
I & 122 & 128 \\
II & 381 & 0 \\
III & 855 & \\
IV & 129 & \\
Data missing & 31 & \\
\hline
\end{tabular}

$A V R$, Aortic valve replacement; $M V R$, mitral valve replacement; $C A B G$, coronary artery bypass grafting; NYHA, New York Heart Association.

MVR recipients, respectively, as shown in Figure 1. Actual/cumulative freedom from valve-related death was $92.5 \% \pm 1.8 \%$ and $92.8 \% \pm 2.2 \%$ for AVR and MVR recipients, respectively.

\section{Functional Class}

At the 20 -year follow-up, $50 \%, 28 \%, 20 \%$, and $2 \%$ of patients who underwent AVR were in New York Heart Association functional class I, II, III, and IV, respectively, compared with $34 \%, 36 \%, 29 \%$, and $2 \%$ of patients who underwent MVR.

\section{Complications}

Complication incidences per patient-year over 20 years' follow-up are summarized in Table 3.

Reoperations. A total of 146 patients required reoperation within the study period. The most common cause of reoperation was structural valve deterioration (SVD), which led to reoperation for 77 patients undergoing AVR and 11 patients undergoing MVR. The incidence of reoperation was $0.9 \%$ per patient-year in each valve position. Valve deterioration was due to stenosis in $10 \%$, insufficiency in $25 \%$, mixed stenosis and insufficiency in $51 \%$, and "no visual damage" in $14 \%$ of cases.

Actuarial freedom from reoperation because of SVD was $61.1 \% \pm 8.5 \%$ and $79.3 \% \pm 6.0 \%$ after AVR and MVR, respectively (Figure 2). (The equivalent actual values were 
TABLE 2. Causes of late mortality

\begin{tabular}{lrr}
\hline & AVR & MVR \\
\hline SVD & 3 & 1 \\
TE & 21 & 3 \\
ACH & 14 & 4 \\
PVE & 8 & 4 \\
Other cardiac & 234 & 47 \\
Noncardiac & 247 & 32 \\
\hline
\end{tabular}

$A V R$, Aortic valve replacement; $M V R$, mitral valve replacement; $S V D$, structural valve deterioration; $T E$, thromboembolic event; $A C H$, anticoagulant-related hemorrhage; $P V E$, prosthetic valve endocarditis.

$85.6 \% \pm 2.2 \%$ and $91.2 \% \pm 2.5 \%$, respectively.) Actuarial freedom from reoperation because of SVD according to age group is shown in Table 4; Figure 3 compares freedom from reoperation because of SVD over time in patients aged more than 65 years and patients aged 65 years or less. There was no early mortality at reoperation for SVD. A further 33 patients required reoperation for prosthetic valve endocarditis (see below), and another 27 patients required reoperation for nonstructural valve dysfunction (mainly paravalvular leak).

Thromboembolic and anticoagulant-related events. Actuarial freedom from thromboembolism at follow-up was $70.8 \% \pm 5.5 \%$ and $71.3 \% \pm 5.7 \%$ after AVR and MVR, respectively. (The equivalent actual values were $84.1 \% \pm$ $1.7 \%$ and $82.9 \% \pm 3.2 \%$, respectively.) Of the patients undergoing AVR, those aged less than 50 years when they received their replacement valve in the aortic position had the highest actuarial freedom from thromboembolic events: $98.8 \% \pm 1.2 \%$; the equivalent values for patients aged 65 years or less and patients aged more than 65 years were $87.5 \% \pm 3.8 \%$ and $34.4 \% \pm 2.5 \%$, respectively.

Actuarial freedom from anticoagulant-related hemorrhage was $83.1 \% \pm 6.8 \%$ and $85.8 \% \pm 4.3 \%$ after AVR or MVR, respectively. (The corresponding actual figures were $91.3 \% \pm 1.8 \%$ and $91.7 \% \pm 2.3 \%$, respectively.) At follow-up, $8 \%$ of the patients undergoing AVR and $40 \%$ of the patients undergoing MVR were receiving anticoagulation.

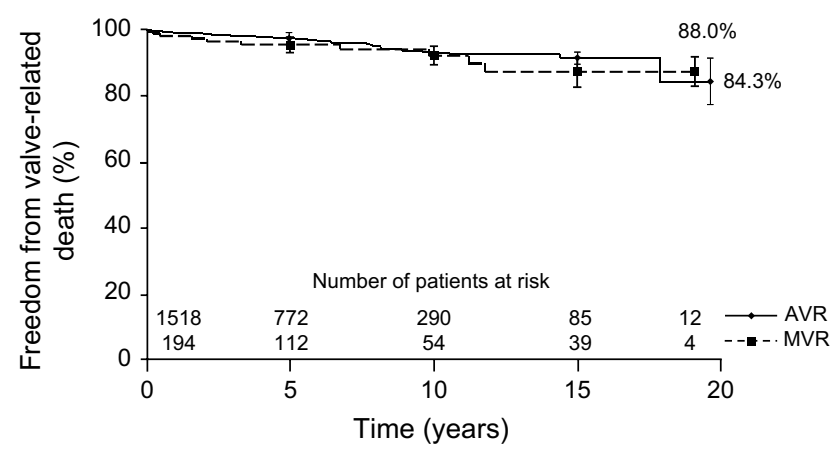

FIGURE 1. Actuarial freedom from valve-related death (according to valve position). $A V R$, Aortic valve replacement; $M V R$, mitral valve replacement.
TABLE 3. Complication incidences per patient-year

\begin{tabular}{llrc}
\hline & & No. & Incidence/patient-year (\%) \\
\hline Reoperation because of SVD & AVR & 78 & 0.9 \\
& MVR & 11 & 0.9 \\
\multirow{2}{*}{ Reoperation because of PVE } & AVR & 24 & 0.3 \\
& MVR & 9 & 0.7 \\
ACH & AVR & 77 & 0.9 \\
& MVR & 13 & 1.0 \\
TE & AVR & 139 & 1.6 \\
& MVR & 26 & 2.2 \\
\hline
\end{tabular}

$S V D$, Structural valve deterioration; $A V R$, aortic valve replacement; $M V R$, mitral valve replacement; $P V E$, prosthetic valve endocarditis; $A C H$, anticoagulant-related hemorrhage; $T E$, thromboembolic event.

Prosthetic valve endocarditis. Actuarial freedom from prosthetic valve endocarditis was $95.1 \% \pm 1.5 \%$ at 20 years after AVR and $91.7 \% \pm 3.1 \%$ after MVR. (Corresponding actual values were $97.3 \% \pm 0.6 \%$ and $94.6 \% \pm 1.8 \%$, respectively.)

\section{Doppler Echocardiography}

Doppler echocardiography can be useful for providing a complete picture of patient outcomes after valve replacement surgery, so we aimed to collect as much long-term postoperative echocardiography data as possible and continued until 2007. Availability is limited, however, especially for the many elderly patients who are resident in nursing homes. There is a wide variation in the completeness of investigations achieved, but all echocardiograms of prosthetic aortic valves include a peak gradient value.

Echocardiography data are available for 1003 AVR recipients: $57 \%$ with 5 years' follow-up, $27 \%$ with 5 to 10 years' follow-up, and $16 \%$ with more than 10 years' follow-up. Less than 1 in 10 patients $(76 / 1003 ; 7.5 \%)$ had peak gradient values greater than $60 \mathrm{~mm} \mathrm{Hg}$, suggesting a gradual valve deterioration. The remaining 927 patients had a mean peak gradient of $30.6 \pm 10.9 \mathrm{~mm} \mathrm{Hg}$ (all valve sizes included).

\section{DISCUSSION}

This article reports data from more than 10,000 patientyears of follow-up over 20 years in approximately 1800

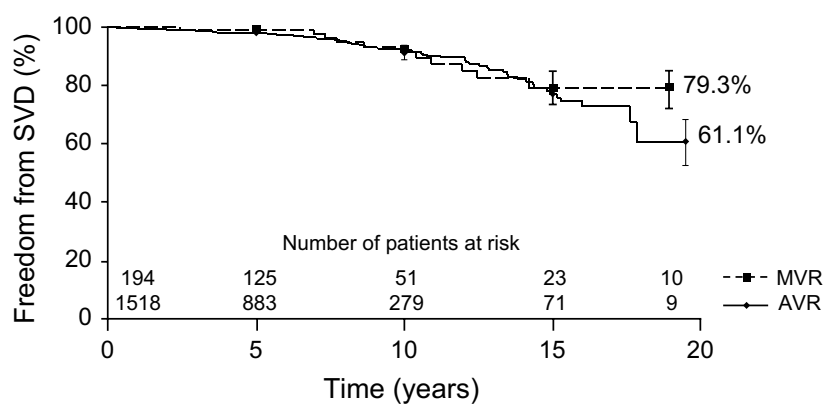

FIGURE 2. Actuarial freedom from reoperation because of SVD (according to valve position). $A V R$, Aortic valve replacement; $M V R$, mitral valve replacement; $S V D$, structural valve deterioration. 
TABLE 4. Actuarial freedom from reoperation because of structural valve deterioration according to age group

\begin{tabular}{lcc}
\hline Age groups & Aortic valve replacement & Mitral valve replacement \\
\hline$\leq 50 \mathrm{y}$ & $37.7 \% \pm 8.6 \%$ & $57.6 \% \pm 1.5 \%$ \\
$51-60 \mathrm{y}$ & $60.7 \% \pm 10.3 \%$ & $80.0 \% \pm 1.9 \%$ \\
$61-70 \mathrm{y}$ & $81.0 \% \pm 5.1 \%$ & $86.3 \% \pm 0.7 \%$ \\
$71-80 \mathrm{y}$ & $97.8 \% \pm 1.2 \%$ & $100 \%(>70 \mathrm{y})$ \\
$>80 \mathrm{y}$ & $100 \%$ & $100 \%(>70 \mathrm{y})$ \\
\hline
\end{tabular}

bioprosthetic heart valve recipients, and the results are consistent with previously published outcomes of the same study at 10-, 15-, and 17-year follow-ups. ${ }^{5-8}$ This is one of the largest published studies of outcomes after bioprosthetic valve replacement to date. Results of such long-term studies have started to emerge in recent years, but evidence of the long-term durability of currently available prosthetic valves is still limited. ${ }^{1-4,8}$ There remain few published studies with sufficiently prolonged follow-up to enable direct comparison between the St Jude Medical Biocor porcine bioprosthesis and other bioprostheses. Even articles such as Jamieson and colleagues' 2005 long-term follow-up ${ }^{2}$ on the Carpentier-Edwards (Edwards Lifesciences, Irvine, Calif) supraannular aortic porcine bioprosthesis reported most outcomes at 15- and 18-year follow-ups. Thus, more data from robust large-scale studies are required to make the best choice of prosthetic valve for each individual patient.

It is also relevant to note that it is difficult to compare outcomes in populations with differing baseline characteristics, and different study reports rarely include all of the same baseline characteristics. ${ }^{13}$ Our results compare well, however, with the few available 20-year publications on bioprosthetic heart valves (key outcomes are summarized in Table 5).

\section{Long-term Survival after Valve Replacement}

Survival in our study was $17.7 \pm 3.3$ for AVR recipients and $16.4 \pm 4.7$ for MVR recipients, which compares favorably with or is comparable to the overall 19-year survival for single bioprosthetic valve replacements according to the United Kingdom Heart Valve Registry Report 2003 (19.92\%; 95\% confidence interval, $18.54-21.34 \%) .{ }^{14}$ It should be noted that it is difficult to compare survival across different patient groups and countries because of the baseline and population differences, as well as other factors that can affect outcomes in valve-replacement recipients, such as the degree of hypertrophy at the time of operation or postoperative hypertension. ${ }^{15}$

Survival over 20 years in Biocor recipients compares well with the few available 20-year publications on bioprosthetic heart valves. The 20-year follow-up study on the CarpentierEdwards supra-annular aortic porcine bioprosthesis reported a survival of $6.8 \% \pm 2.0 \%$, compared with our observed survival of $17.7 \% \pm 3.3 \%$ in aortic Biocor recipients. ${ }^{2}$ There is no clear explanation for the apparent difference in
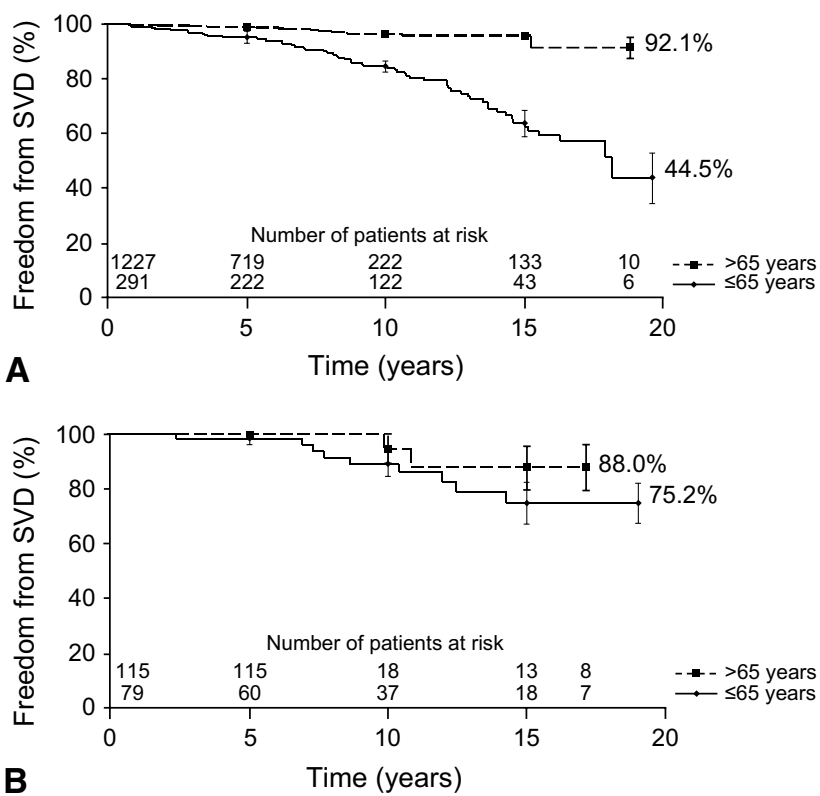

FIGURE 3. Actuarial freedom from reoperation because of SVD according to age in (A) AVR recipients and (B) MVR recipients. AVR, Aortic valve replacement; $M V R$, mitral valve replacement; $S V D$, structural valve deterioration.

survival with Biocor versus the Carpentier-Edwards supraannular valve, because reported patient characteristics such as age (slightly higher in our group) and baseline coronary artery disease/CABG are similar in both study populations. ${ }^{2}$

The study of 20-year outcomes using the Hancock II porcine bioprosthesis (Medtronic, Minneapolis, Minn) reported overall survival similar to our study $(19 \% \pm 4 \%) .{ }^{4}$ Borger and coworkers ${ }^{4}$ also reported a 20 -year survival of $6 \% \pm$ $3 \%$ in 559 mitral valve recipients, ${ }^{4}$ compared with our observed survival of $16.4 \% \pm 4.7 \%$ in 194 patients, although these data should be interpreted with caution because of the small patient numbers.

\section{Long-term Durability}

The most important quality of a bioprosthesis is durability, and long-term clinical studies are essential for evaluating this. ${ }^{13}$ It is impossible to be sure that a device performing well in preclinical animal studies will continue to do so in the long term when implanted in humans, as illustrated by the failure of the sheep model to reveal a design flaw that led to leaflet abrasion in subsequent clinical trials. ${ }^{16,17}$ Follow-up of less than 15 years has limited value in assessing bioprosthesis durability, and at least 15 to 20 years' follow-up is required. ${ }^{13}$

The actuarial freedom from SVD in aortic valve recipients at 18 years in the 20-year Carpentier-Edwards supraannular valve study was $64 \% \pm 4 \%$ (with a corresponding actual value of $86 \% \pm 1 \%$ ), which is comparable to our current 20-year actuarial freedom from reoperation because of SVD of $61.1 \% \pm 8.5 \%$ (and actual freedom of 
TABLE 5. Long-term survival/durability outcomes (17-20 years) of large-scale ( $\mathrm{n}>1000$ patients) studies of bioprosthetic heart valves for aortic valve replacement

\begin{tabular}{|c|c|c|c|c|c|}
\hline Follow-up time & Bioprosthesis, reference & Mean age & $\begin{array}{l}\text { Actuarial } \\
\text { survival }\end{array}$ & $\begin{array}{c}\text { Actuarial freedom } \\
\text { from valve-related } \\
\text { death } \\
\end{array}$ & $\begin{array}{l}\text { Actuarial freedom } \\
\text { from reoperation } \\
\text { because of SVD } \\
\end{array}$ \\
\hline \multirow[t]{4}{*}{$20 \mathrm{y}$} & $\begin{array}{l}\text { St Jude Medical Biocor porcine } \\
\text { bioprosthesis (St Jude Medical, } \\
\text { St Paul, Minn), current study }\end{array}$ & $70.8 \pm 10.9 y$ & $17.7 \% \pm 3.3 \%$ & $84.3 \% \pm 6.9 \%$ & $\begin{array}{l}\text { Overall: } 61.1 \% \pm 8.5 \% \\
\text { Age }<65 \text { y: } 44.5 \% \pm 9.2 \% \\
\text { Age } \geq 65 \text { y: } 92.1 \% \pm 3.9 \%\end{array}$ \\
\hline & $\begin{array}{l}\text { Carpentier-Edwards SAV porcine } \\
\text { bioprosthesis (Edwards } \\
\text { Lifesciences, Irvine, Calif), } \\
\text { Jamieson and colleagues }{ }^{2}\end{array}$ & $68.8 \pm 10.9$ y & $6.8 \% \pm 2.0 \%$ & Not reported & Not reported \\
\hline & $\begin{array}{l}\text { Hancock II porcine bioprosthesis, } \\
\text { Borger and colleagues }{ }^{4}\end{array}$ & $67 \pm 11 \mathrm{y}$ & $19 \% \pm 4 \%$ & Not reported & $\begin{array}{l}\text { Overall: Not reported } \\
\text { Age }<65 \text { y: } 39 \% \pm 9 \% \\
\text { Age } \geq 65 \text { y: } 73 \% \pm 16 \%\end{array}$ \\
\hline & $\begin{array}{l}\text { Carpentier-Edwards Perimount } \\
\text { pericardial bioprosthesis, } \\
\text { clinical communication }^{22}\end{array}$ & $64.9 \pm 12 y$ & Not reported & $67.9 \% \pm 6.6 \%$ & $\begin{array}{l}\text { Overall: Not reported } \\
\text { Age } \geq 65 \text { y: } 81.5 \% \pm 9.6 \% \\
\text { Age }>70 \text { y: } 69.9 \% \pm 20.5 \%\end{array}$ \\
\hline \multirow[t]{2}{*}{$18 \mathrm{y}$} & $\begin{array}{l}\text { Carpentier-Edwards SAV porcine } \\
\text { bioprosthesis, Jamieson and } \\
\text { colleagues }^{2}\end{array}$ & $68.8 \pm 10.9 y$ & $15.8 \% \pm 1.6 \%$ & $78.4 \% \pm 2.9 \%$ & $\begin{array}{l}\text { (Reported as freedom from SVD) } \\
\text { Overall: } 64.0 \% \pm 3.6 \% \\
\text { Age } \leq 50 \text { y: } 31.9 \% \pm 6.3 \% \\
\text { Age } 51-60: 51.0 \% \pm 7.0 \% \\
\text { Age } 61-70 \text { y: } 77.6 \% \pm 4.9 \% \\
\text { Age }>70 \text { y: } 94.6 \% \pm 2.3 \%\end{array}$ \\
\hline & $\begin{array}{l}\text { Carpentier-Edwards Perimount } \\
\text { pericardial bioprosthesis, } \\
\text { Aupart and colleagues }{ }^{18}\end{array}$ & $72.6 \mathrm{y}$ & $22 \% \pm 4 \%$ & $82 \% \pm 3 \%$ & $68 \% \pm 12 \%$ \\
\hline \multirow[t]{2}{*}{$17 \mathrm{y}$} & $\begin{array}{l}\text { St Jude Medical Biocor porcine } \\
\text { bioprosthesis, Mykén }{ }^{8}\end{array}$ & $70.8 \pm 10.9 y$ & $28.2 \% \pm 3.7 \%$ & $89.9 \% \pm 3.0 \%$ & $73.9 \% \pm 4.1 \%$ \\
\hline & $\begin{array}{l}\text { Mitroflow pericardial } \\
\text { bioprosthesis, Yankah } \\
\text { and colleagues }\end{array}$ & $72.4 \pm 8.4 \mathrm{y}$ & $23.2 \% \pm 2 \%$ & $92.0 \% \pm 2.2 \%$ & $67.0 \% \pm 4.9 \%$ \\
\hline
\end{tabular}

$S V D$, Structural valve deterioration; $S A V$, supra-annular aortic valve.

$85.6 \% \pm 2.2 \%$ ) after implantation of the Biocor valve in the aortic position. $^{2}$ As reported previously, actuarial freedom from reoperation because of SVD was $73.9 \% \pm 4.1 \%$ at 17 years after AVR using the Biocor bioprosthesis. ${ }^{2,8}$

Borger and coworkers ${ }^{4}$ report of 20 -year outcomes using the Hancock II porcine bioprosthesis includes data on 1010 aortic valve recipients with a mean age of 67 years. This study reports actuarial freedom from reoperation for SVD in AVR of 39\% $\pm 9 \%$ for patients aged less than 65 years and $73 \% \pm 16 \%$ for patients aged 65 years or more. Our results for the same period of time are $44.5 \% \pm 9.2 \%(\leq 65$ years) and $92.1 \% \pm 3.9 \%$ (>65 years), which are superior, particularly in those aged more than 65 years. This result in patients aged more than 65 years at 20 years' follow-up also compares favorably with a result of $85 \% \pm 8 \%$ from an 18-year study on the Carpentier-Edwards Perimount bioprosthesis (Edwards Lifesciences) in the aortic position. ${ }^{18}$

Indeed, our reported freedom from SVD after implantation of the Biocor valve compares well with 14-year ${ }^{19}$ and 15 -year ${ }^{20}$ follow-up data using alternative bioprostheses. Marchand and colleagues ${ }^{19}$ reported $69 \% \pm 5 \%$ actuarial freedom from SVD in all patients (mean age 61 years) over 14 years with the Carpentier-Edwards Perimount valve in the mitral position, whereas a value of $79.3 \% \pm 6.0 \%$ (mean age 65 years) was obtained in our study with the Biocor bioprosthesis. David and colleagues ${ }^{20}$ reported a 15-year actual freedom from SVD of $89 \% \pm 4 \%$ in MVR recipients of the Hancock II bioprosthesis aged more than 65 years; this age group's actual freedom from SVD was $97 \% \pm 2 \%$ in our study, which had a longer follow-up. In patients aged less than 65 years with the valve in the mitral position, David and colleagues reported actual freedom from SVD to be $76 \% \pm 5 \%$ at 15 years' follow-up, compared with our actual freedom from SVD of $85 \% \pm 4 \%$ over a longer period of time.

According to all long-term follow-ups, SVD occurs earlier in the mitral position than in the aortic position. However, the Biocor porcine bioprosthesis has previously shown comparable durability in both mitral and aortic positions. ${ }^{8,7}$ Borger and coworkers ${ }^{4}$ reported 20-year actuarial freedom from SVD with Hancock II mitral valves of $27 \% \pm 9 \%$ and $59 \% \pm 11 \%$ in patients aged less than and more than 65 years, respectively. The actuarial freedom from SVD in our study of $75.2 \% \pm 7.6 \%$ and $88.0 \% \pm 8.1 \%$ in the 
same respective age groups demonstrates a considerable difference in favor of the Biocor valve.

Minami and colleagues ${ }^{21}$ reported the 19-year results for the Mitroflow Synergy pericardial valve (Sorin Group Canada Inc, Burnaby, BC, Canada) $(\mathrm{n}=1516)$. The results for actuarial freedom from endocarditis, tear, and valve degeneration showed that implantations should be restricted to patients aged more than 75 years, whereas the Biocor bioprosthesis has shown good durability over the same time scale in patients aged more than 65 years.

\section{Long-term Complications}

Complications using the Biocor valve also compared favorably with alternative bioprostheses. Our observed actuarial freedom from thromboembolism after AVR $(70.8 \% \pm$ $5.5 \%$ ) was comparable to that from the 20-year results using the Hancock II bioprosthesis $(79 \% \pm 3 \%)$ and 18 -year results using the Carpentier-Edwards supra-annular valve $(66.0 \% \pm 5.1 \%)^{2,4}$ The fact that our results range from $98.8 \% \pm 1.2 \%$ in patients aged less than 50 years at implantation to $34.4 \% \pm 2.5 \%$ in patients aged more than 65 years suggests that the frequency of thromboembolic events may be associated more with age than valve.

Actuarial freedom from prosthetic valve endocarditis at 20 years with the Hancock II valve was $91 \% \pm 5 \%$ in AVR recipients and $85 \pm 5 \%$ in MVR recipients, ${ }^{4}$ compared with $95.1 \% \pm 1.5 \%$ (AVR) and $91.7 \% \pm 3.0 \%$ (MVR) with the Biocor bioprosthesis. Similarly, Jamieson and coworkers ${ }^{2}$ reported actuarial freedom from prosthetic valve endocarditis of $92 \% \pm 2 \%$ (and an actual value of $97 \% \pm 1 \%$ ) at 18 years' follow-up using the Carpentier-Edwards supra-annular valve for AVR, which is more or less identical to our result of $95.1 \% \pm 1.5 \%$ (actual: $97.3 \% \pm$ $0.6 \%$ ). Actuarial freedom from anticoagulant-related hemorrhage was $89 \% \pm 2 \%$ (actual: $94 \% \pm 1 \%$ ) at 18 years in the same study; our value of $83.1 \% \pm 6.8 \%$ (actual: $91.3 \% \pm 1.8 \%$ ) at 20 years is similar (Borger and colleagues ${ }^{4}$ did not report freedom from anticoagulant-related hemorrhage). ${ }^{2}$

\section{CONCLUSIONS}

This study provides some of the most robust evidence available on long-term outcomes after bioprosthetic heart valve replacement. Long-term durability is the most important parameter when evaluating bioprosthesis, and these results clearly demonstrate the excellent durability of the $\mathrm{St}$ Jude Medical Biocor porcine bioprosthesis over 20 years in both aortic and mitral positions. These data are consistent with previous reports at 10-, 15-, and 17-years' follow-up using the Biocor valve and provide a valuable addition to the limited number of long-term study reports that have been published to date.

\section{References}

1. Bonow RO, Carabello BA, Chatterjee K, de Leon AAC Jr, Faxon DP, Freed MD, et al. ACC/AHA 2006 guidelines for the management of patients with valvular heart disease: a report of the American College of Cardiology/American Heart Association Task Force on Practice Guidelines (writing Committee to Revise the 1998 guidelines for the management of patients with valvular heart disease) developed in collaboration with the Society of Cardiovascular Anesthesiologists endorsed by the Society for Cardiovascular Angiography and Interventions and the Society of Thoracic Surgeons. J Am Coll Cardiol. 2006;48:e1-148.

2. Jamieson WRE, Burr LH, Miyagishima RT, Germann E, Macnab JS, Stanford E, et al. Carpentier-Edwards supra-annular aortic porcine bioprosthesis: clinical performance over 20 years. J Thorac Cardiovasc Surg. 2005;130: 994-1000

3. Yankah C, Schubel J, Buz S, Siniawski H, Hetzer R. Seventeen-year clinical results of 1,037 Mitroflow pericardial heart valve prostheses in the aortic position. J Heart Valve Dis. 2005;14:172-80.

4. Borger MA, Ivanov J, Armstrong S, Christie-Hrybinsky D, Feindel CM, David TE. Twenty-year results of the Hancock II bioprosthesis. J Heart Valve Dis. 2006;15:49-56.

5. Mykén PS, Caidahl K, Larsson S, Berggren HE. 10-year experience with the Biocor porcine bioprosthesis in the aortic position. J Heart Valve Dis. 1994;3:648-56.

6. Mykén PS, Caidahl K, Larsson S, Berggren HE. 10-year experience with the Biocor porcine bioprosthesis in the mitral position. J Heart Valve Dis. 1995;4:63-9.

7. Mykén P, Bech-Hanssen O, Phipps B, Caidahl K. Fifteen years follow up with the St. Jude Medical Biocor porcine bioprosthesis. J Heart Valve Dis. 2000;9:415-22.

8. Mykén P. Seventeen-year experience with the St. Jude Medical Biocor porcine bioprosthesis. J Heart Valve Dis. 2005;14:486-92.

9. Kirali K, Guler M, Tuncer A, Daglar B, Ipek G, Isik O, et al. Fifteen-year clinical experience with the Biocor porcine bioprostheses in the mitral position. Ann Thorac Surg. 2001;71:811-5.

10. Pomerantzeff PM, Brandao CM, Albuquerque JM, Stolf NA, Grinberg M, Oliveira SA. Long-term follow up of the Biocor porcine bioprosthesis in the mitral position. J Heart Valve Dis. 2006;15:763-7.

11. Edmunds LH Jr, Clark RE, Cohn LH, Grunkemeier GL, Miller DC, Weisel RD Guidelines for Reporting Morbidity and Mortality After Cardiac Valvular Operations. Ad Hoc Liaison Committee for Standardizing Definitions of Prosthetic Heart Valve Morbidity of The American Association for Thoracic Surgery and The Society of Thoracic Surgeons. J Thorac Cardiovasc Surg. 1996;112:708-11.

12. Bodnar E, Blackstone EH. An "actual" problem: Another issue of apples and oranges. J Heart Valve Dis. 2005;14:706-8.

13. Rahimtoola $\mathrm{SH}$. The next generation of prosthetic heart valves needs a proven track record of patient outcomes at $\geq 15$ to 20 years. J Am Coll Cardiol. 2003;42:1720-1.

14. The United Kingdom Heart Valve Registry Report 2003. London: United Kingdom Heart Valve Registry; 2005.

15. Lund O, Bland M. Risk-corrected impact of mechanical versus bioprosthetic valves on long-term mortality after aortic valve replacement. J Thorac Cardiovasc Surg. 2006;132:20-6.

16. Vesely I. The evolution of bioprosthetic heart valve design and its impact on durability. Cardiovasc Pathol. 2003;12:277-86.

17. Schoen FJ. Pathologic findings in explanted clinical bioprosthetic valves fabricated from photooxidized bovine pericardium. J Heart Valve Dis. 1998;7: 174-9.

18. Aupart MR, Mirza A, Meurisse YA, Sirinelli AL, Neville PH, Marchand MA Perimount pericardial bioprosthesis for aortic calcified stenosis: 18-year experience with 1,133 patients. J Heart Valve Dis. 2006;15:768-76.

19. Marchand MA, Aupart MR, Norton R, Goldsmith IR, Pelletier LC, Pellerin M, et al. Fifteen-year experience with the mitral Carpentier-Edwards PERIMOUNT pericardial bioprosthesis. Ann Thorac Surg. 2001;71(5 Suppl.): S236-9.

20. David TE, Ivanov J, Armstrong S, Feindel CM, Cohen G. Late results of heart valve replacement with the Hancock II bioprosthesis. I Thorac Cardiovasc Surg. 2001;121:268-77.

21. Minami K, Zittermann A, Schulte-Eistrup S, Koertke H, Körfer R. Mitroflow Synergy prostheses for aortic valve replacement: 19 years experience with 1516 patients. Ann Thorac Surg. 2005;80:1699-705.

22. Clinical communiqué: 20-year results: Carpentier-Edwards Perimount aortic pericardial bioprosthesis. Irvine, CA: Edwards Lifesciences; 2003. Available at: http://www.edwards.com/products/heartvalves/perimountaorticcommuniquepdf.htm. Accessed October 18, 2007 